\title{
Synchrony and mutual stimulation of yeast cells during fast glycolytic oscillations
}

\author{
Miguel A. Aon, ${ }^{1 *} \uparrow$ Sonia Cortassa, ${ }^{1} \dagger$ Hans V. Westerhoff ${ }^{1,2}$ and Karel van Dam ${ }^{1}$ \\ ${ }^{1}$ E. C. Slater Institute for Biochemical Research and Biotechnological Centre, University of Amsterdam, \\ Plantage Muidergracht 12, 1018 TV Amsterdam, The Netherlands \\ ${ }^{2}$ Netherlands Cancer Institute, Plesmanlaan 121, 1066 CX Amsterdam, The Netherlands
}

(Received 30 April 1992; accepted 6 July 1992)

\begin{abstract}
Cell synchrony was investigated during glycolytic oscillations in starved yeast cell suspensions at cell densities ranging from $2 \times 10^{6}-5 \times 10^{7}$ cells $\mathrm{ml}^{-1}$. Oscillations in $\mathrm{NAD}(\mathrm{P}) \mathrm{H}$ were triggered by inhibition of mitochondrial respiration when intracellular $\mathrm{NAD}(\mathrm{P}) \mathrm{H}$ had reached a steady state after glucose addition. Before macroscopic damping of the oscillations, individual yeast cells oscillated in phase with the cell population. After oscillations had damped out macroscopically, a significant fraction of the cells still exhibited oscillatory dynamics, slightly out-ofphase. At cell concentrations higher than $10^{7}$ cells $\mathrm{ml}^{-1}$ the dependence upon cell-density of (i) the damping of glycolytic oscillations and (ii) the amplitude per cell suggested that cell-to-cell interaction occurred. Most importantly, at cell densities exceeding $10^{7}$ cells ml-1 $^{-1}$ the damping was much weaker. A combination of modelling studies and experimental analysis of the kinetics of damping of oscillations and their amplitude, with and without added ethanol, pyruvate or acetaldehyde, suggested that the autonomous glycolytic oscillations of the yeast cells depend upon the balance between oxidative and reductive (ethanol catabolism) fluxes of NADH, which is affected by the extracellular concentration of ethanol. Based on the facts that cell (i) excrete ethanol, (ii) are able to catabolize external ethanol, and (iii) that this catabolism affects their tendency to oscillate, we suggest that the dependence of the oscillations on cell density is mediated through the concentration of ethanol in the medium.
\end{abstract}

\section{Introduction}

The problem of coherence in behaviour of cell populations is of great importance for understanding several biological problems ranging from proliferation to development (Lloyd et al., 1982). Since there is variability of cycle time during growth even in genetically homogeneous cell populations, the problem exists of extrapolating the behaviour shown by heterogeneous cell populations to the single cell level (Lloyd et al., 1982). When the frequency and phases of individual oscillating cells are the same, the population is considered to be mutually synchronous (Winfree, 1980). When cells remain in phase over many oscillatory periods, they must be synchronized by some mechanism, unless the differ-

* Author for correspondence (present address as below). Tel. 81310122 ext. 354; fax 81 311462; e-mail BITNET. RNFARIAS@CERIDE.

\footnotetext{
† Present address: Instituto Superior de Investigaciones Biológicas (INSIBIO-CONICET), Departamento Bioquímica de la Nutrición, Universidad Nacional de Tucumán, Chacabuco 461, 4000 San Miguel de Tucumán, Argentina.
}

ences in magnitude of the kinetic parameters between individual cells are very slight.

Glycolytic oscillations provide an example of selforganization and periodicity (Ghosh et al., 1971; Hess \& Boiteux, 1971; Nicolis \& Prigogine, 1977). For glycolytic oscillations, yeast is an adequate experimental system for the study of collective behaviour such as cell synchronization (Aldridge \& Pye, 1976; Chance et al., 1973; Ghosh et al., 1971). Although previous studies of yeast cell synchronization during glycolytic oscillations suggested that cell interaction would involve a diffusible glycolytic intermediate (Aldridge \& Pye, 1976; Ghosh et al., 1971), the metabolic basis of that interaction remains elusive. Both pyruvate and acetaldehyde were discarded as candidates for the synchronizing agent on the basis that their extracellular concentrations remained considerably below those known to induce phase shifts in oscillatory behaviour (Winfree, 1980). Mitochondrial functions may exert some control on the dynamic behaviour of glycolysis in starved yeast (Aon et al., 1991), probably through cytoplasmic ATP and/or NAD ${ }^{+}$pools. Modulation of the level of cytosolic ATP by mito- 
chondria might in turn modulate the dynamic behaviour of glycolysis to become oscillatory. Mitochondrial NADH dehydrogenase and the glycolytic steps associated with NADH reoxidation downstream of pyruvate appear to provide another control level of glycolysis dynamics (Aon et al., 1991).

The present work addresses three questions. (i) To what extent may the dynamic behaviour of a single yeast cell be deduced from that of the cell population exhibiting macroscopic oscillations? (ii) What is the metabolic basis of synchrony between individual yeast cells? (iii) What determines the duration and amplitude of NAD(P)H oscillations in yeast cell populations?

\section{Methods}

Micro-organism and growth conditions. Saccharomyces cerevisiae, diploid strain X2180

$$
\left(\frac{M A T \mathbf{a}}{M A T \alpha} \frac{\text { suc2 }}{\text { suc2 }} \frac{\text { mal }}{\text { mal }} \frac{\text { mel }}{\text { mel }} \frac{\text { gal2 }}{\text { gal2 } 2} \frac{\text { cup } 1}{\text { cupl } 1}\right)
$$

(Yeast Genetic Stock Center, Berkeley, Calif., USA) was maintained and grown as described previously (Aon et al., 1991; Oehlen et al., 1990). Unless otherwise specified, cells were harvested by filtration at mid-exponential phase. They were then washed twice with $0.1 \mathrm{M}$ potassium phosphate buffer, $\mathrm{pH} 6 \cdot 8$, resuspended in the same buffer at a concentration of $2-4 \times 10^{6}$ cells $\mathrm{ml}^{-1}$ and starved for $3 \mathrm{~h}$ in a rotary shaker (120 r.p.m.) at $30^{\circ} \mathrm{C}$ (Aon et al., 1991). Centrifugal elutriation of cells harvested at mid-exponential phase was done as described previously (Oehlen et al., 1990). The percentage of budded and single elutriated cells did not change during the starvation period.

Measurement of $N A D(P) H$ kinetics. Cells were harvested as described above. Intracellular nicotinamide nucleotide reduction was monitored with an Eppendorf fluorimeter at an excitation wavelength of $316-366 \mathrm{~nm}$, emission being measured at $400-450 \mathrm{~nm}$. The experiments were done at various cell concentrations in a thermostated cuvette at $25^{\circ} \mathrm{C}$ with stirring (Aon et al., 1991). All the fluorescence traces shown represent a typical result corresponding to duplicates or triplicates for each cell batch and for three independent experiments. The fluorimeter was calibrated by addition of various NADH concentrations to inactive cell suspensions at different densities.

Respiration measurements. Yeast cell suspensions at similar density, $\mathrm{pH}$ and temperature as in the fluorescence measurements were assayed in parallel for oxygen uptake with a Clark oxygen electrode (Yellow Springs Instruments) in a magnetically stirred oxygraph vessel as described previously (Aon et al., 1991).

Image analysis of intrinsic $N A D(P) H$ fluorescence dynamics at the single cell and cell population levels. Oscillations were induced as previously described (Aon et al., 1991). Briefly, starved yeast cell suspensions in $0.1 \mathrm{M}$-phosphate buffer, $\mathrm{pH} 6.8$ were incubated in the presence of $20 \mathrm{~mm}$-glucose ( $3 \mathrm{~min}$ ) and after addition of $10 \mathrm{mM}-\mathrm{KCN}$, which induces oscillations, a $6 \mu \mathrm{l}$ sample was placed between a slide and coverslip and sealed. Under these conditions, a single cell layer was obtained. Cells were excited at $340 \mathrm{~nm}$, the emission being measured at $450 \mathrm{~nm}$. Pictures of the cells (10 s fixed exposure time) were taken at regular intervals (12 s) and analysed by image processing (Image 1.29; W. Rasband, National Institute of Mental Health, Rockville, Md., USA) with an Apple MacIntosh II CI computer. The ability of the cells to oscillate was tested by fluorimetry in the same cell suspension as described above. For analysis at the cell population level, each picture was sampled in five places with a fixed square surface containing $\sim 20$ fluorescent cells and the mean and standard deviation of the total fluorescence intensity was determined. The mean and standard deviation of fluorescence intensity were averaged over the five samples. The averaging of standard deviations was assumed to be valid since the between-samples variance was not significantly larger than the within-samples variance.

To avoid artifacts of photographic procedures and photobleaching, a glass capillary ( $\sim 0 \cdot 1 \mathrm{~mm}$ diam.) filled with $0 \cdot 1 \mathrm{~mm}-\mathrm{NADH}$ was used as an internal standard. Two readings were taken from the internal standard, and the mean and standard deviation calculated. From the values of the internal standard the values of the mean and standard deviation of the cell population were subtracted. The rationale behind this procedure is to refer the oscillations in brightness of the cell population to the internal standard (see below). For analysis at the single cell level, six individual cells were chosen and the temporal changes in light intensity emission with respect to the internal standard were followed as described for the cell population.

Viability tests on the yeast cells by methylene blue $\left(5 \mathrm{mg} \mathrm{ml}^{-1}\right)$ exclusion in the presence of UV light showed no change with respect to the control (exposed to normal light) over the same time interval as in the experiment described above. This result rules out possible artifacts introduced by UV light damage to the cells leading to loss of cell viability. We also checked that under these conditions (starved yeast cells suspended in buffer without nitrogen source and exposed to glucose only) no cell growth occurs (Galazzo \& Bailey, 1989).

Oscillations were induced in very dense cell suspensions as described above (excitation at $340 \mathrm{~nm}$, the emission being measured at $450 \mathrm{~nm}$ ). Video films (25 average frames per second) were made with a Zeiss Universal photomicroscope equipped for epifluorescence with a $200 \mathrm{~W}$ high pressure mercury arc lamp, 100/1.3 neofluar lens and an image intensifier (Videoscope, Washington, DC, USA) with a CCD camera (Grundig). The time sequence of fluorescence changes in single cells was determined using pictures taken from video films at regular time intervals. Images were analysed by image processing (Image 1.29 ) with an Apple MacIntosh II CI computer. The fluorescence emitted by the individual cells was evaluated as the grey level occurring at the highest frequency and normalized per unit of fluorescent area to allow comparison between different cells.

\section{Results}

\section{Dependence of glycolytic oscillations on cell density}

To investigate what affects the synchrony of cyanideinduced oscillations of individual cells in a population of yeast cells, we added glucose to semi-anaerobic, starved yeast cells and waited for the intracellular NAD(P)H fluorescence to become steady. To examine the extent to which, under these conditions, the cells were oscillation prone, we perturbed the metabolism of all cells simultaneously. We added cyanide with the effect of inducing transient oscillations in NAD(P)H fluorescence (Aon et al., 1991). This experiment was done at various cell densities to investigate if individual cells influence each other. The amplitude and damping of glycolytic oscillations depended upon cell density (Fig. $1 a$ ), while the oscillatory period was independent of that parameter 

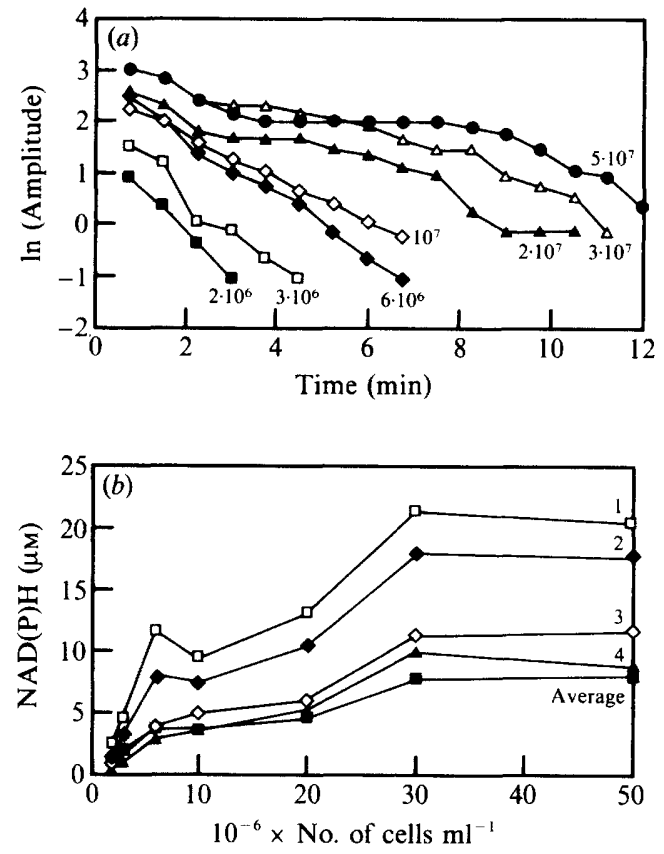

Fig. 1. Dependence on cell density of the amplitude of glycolytic oscillations and damping in starved yeast cells. Yeast cells were grown, harvested and starved as described in Methods. The fluorescence of $\mathrm{NAD}(\mathrm{P}) \mathrm{H}$ in yeast cell suspensions at different densities after starvation was followed as described in Methods. (a) Oscillations were triggered by adding $10 \mathrm{mM}-\mathrm{KCN}$ after glucose $(20 \mathrm{~mm})$ at $2 \times 10^{6}(\square)$, $3 \times 10^{6}(\square), 6 \times 10^{6}(\diamond)$ to $10^{7}(\diamond)$ cells $\mathrm{ml}^{-1}$, and $15 \mathrm{mM}-\mathrm{KCN}$ at $2 \times 10^{7}(\Delta), 3 \times 10^{7}(\triangle)$ to $5 \times 10^{7}(\bullet)$ cells $\mathrm{ml}^{-1}$. The natural logarithm (ln) of the amplitude of the oscillations [in $\mu \mathrm{M}-\mathrm{NAD}(\mathrm{P}) \mathrm{H}]$ was analysed as a function of time and cell concentration, assuming a single exponential decay $\left(A_{\mathrm{NADH}}=A \mathrm{o} e^{-\gamma t} ; \gamma\right.$ being the damping factor, $A \mathrm{o}$ the initial amplitude of the oscillatory fluorescence signal and $t$, time). (b) The amplitude of the first four oscillatory cycles (1-4) and the average of the amplitude of all the oscillatory cycles detected at each cell density plotted as a function of cell concentration. $\square$, First oscillatory cycle; $\diamond$, second; $\diamond$, third; $\boldsymbol{\Delta}$, fourth. $\boldsymbol{\square}$, Average of all oscillatory cycles.

(not shown). The amplitude of the oscillations decreased rapidly at low cell densities and quite slowly at higher cell densities, especially during the first few minutes. At high cell densities, there were extended regions in the kinetics of amplitude decrease of the oscillations, where the cells either oscillated in a sustained way or with little amplitude decrease for several minutes (Fig. 1a). Most notably, at cell densities of $5 \times 10^{7}$ cells ml $^{-1}$, no damping was noticed for $6 \mathrm{~min}$ (Fig. $1 a$ ).

The amplitude of the first four periods of NAD(P)H oscillations was investigated as a function of cell density (Fig. $1 b$ ). Up to $5 \times 10^{6}$ cells $\mathrm{ml}^{-1}$, the amplitude increased almost linearly with cell density. At higher densities a non-linear increase was observed, reaching a plateau at $5 \times 10^{7}$ cells $\mathrm{ml}^{-1}$.

\section{Transient synchrony of yeast cells during glycolytic oscillations}

The observation that damping decreased with increasing cell densities, and the occurrence of more sustained oscillations during a certain time period at high cell densities, suggested some interaction between cells. Did this interaction go as far as to result in active synchronization of the oscillations of individual cells, e.g. by a periodic extracellular trigger? This question of dynamic coherence, i.e. whether the whole yeast cell population oscillated as a single unit, was analysed by fluorescence microscopy of intracellular NAD(P)H fluorescence. The fluorescence intensity of individual cells and the standard deviation thereof around the mean intensity were quantified by image analysis of pictures taken at regular intervals of $12 \mathrm{~s}$. Initially, the fluorescence behaviour of six individual cells (Fig. 2a,c) showed dynamic behaviour similar to the average fluorescence behaviour of the cell population (Fig. $2 b$ and panel $\mathrm{i}$; note that at the microscope stage, temperature was not perfectly controlled, causing some deviation of the oscillation frequency). However, as the oscillations damped at the cell population level, individual cells continued to exhibit oscillatory behaviour, whilst some of them began to run out of phase with the others (Fig. 2a,c). That single cells still showed oscillatory behaviour after long-term exposure to glucose ( $25 \mathrm{~min}$ ) and $\mathrm{KCN}(22 \mathrm{~min})$ was confirmed by image analysis of single cells from video films (Fig. 3). The same cell preparation analysed by fluorimetry after $20 \mathrm{~min}$ in the presence of glucose and $\mathrm{KCN}$ exhibited macroscopically damped oscillations (Fig. 3, panel i). Furthermore, at each time point the standard deviation of the distribution of the fluorescence emitted by the cells increased with time, suggesting higher cellular heterogeneity (results not shown from analysis of the data in Fig. 2b). This increase in heterogeneity is in agreement with disperse dynamic behaviour at the single cell level and a loss of mutual synchrony, i.e. oscillations in single cells run out of phase.

\section{Basis for sustained synchrony}

In the following we evaluate the contribution of the loss of mutual synchrony to the macroscopic damping of oscillations. If we assume that the temporal coherence between cells is broken by heterogeneity and that there is interaction between cells, where does heterogeneity arise - at the signal itself, or at metabolic differences between cells that normally exist in genetically homogeneous populations? And, in the latter case, what is the mechanism of the intercellular communication noted in Fig. 1? In order to answer these questions new 


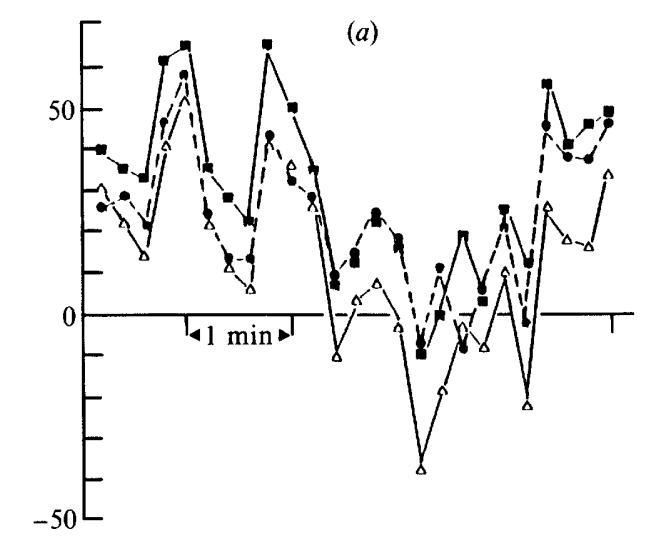

experiments were designed and mathematical modelling performed.

Heterogeneity introduced by dispersion of cells over the cell cycle does not explain damping of the oscillations

Non-starved, nearly homogeneous populations of both 'single' $(96 \%)$ cells and of 'budded' $(82 \%)$ cells, as obtained by centrifugal elutriation, oscillated after starvation, glucose and then cyanide addition (results not shown). This suggested that triggering of oscillations is independent of cell cycle stage. Budded cells resembled the control, non-elutriated cells, in the kinetics of damping of the oscillations and in the appearance of periods in which the damping was drastically reduced. However, 'single' cells showed a somewhat faster damping than the control, non-elutriated, cells.

\section{Heterogeneity in oscillatory dynamics contributes to the macroscopic damping of the oscillations}

The results in Fig. 3 show that after macroscopic damping of the oscillations, it is not realistic to extrapolate from cell population to single cell behaviour. Some individual cells still show changes in fluorescence long after the macroscopic oscillations have damped out completely.

In order to take this into account, the 'cosubstrate' (glucose and ethanol) model was formulated. This model, to be reported in more detail elsewhere, took into account the main aspects of glycolysis, ATP and NADH metabolism. It simulated the observed cyanide-induced NAD(P)H oscillations with the experimentally observed frequency. Further simulation studies showed that if cells in a synchronized (in phase) population exhibit, individually, autonomous sustained oscillations, even if they are heterogeneous in their permeability to ethanol, they will not show damping when averaged (results not shown). This is in agreement with the notion that heterogeneity in cellular permeability to ethanol within the range of high permeabilities does not induce changes in dynamics. On the other hand, a cell population heterogeneous in other kinetic constants of glycolysis, and consequently showing a mixture of autonomous damped and sustained oscillations, tends to dampen the

Fig. 2. Image analysis from pictures of starved yeast under oscillatory conditions at the single and cell population levels. Starved yeast cells were prepared as described in Methods. Pictures of yeast cells $\left(10^{7}\right.$ cells $\left.\mathrm{ml}^{-1}\right)$ metabolizing glucose under oscillatory conditions were taken at regular intervals (12 s). The bars attached to the experimental points $(\bullet, b)$ represent SEM values for the cell population, and the different symbols $(\boldsymbol{\square}, \bullet, \Delta)$ in $(a)$ and $(c)$ correspond to different individual cells. Panel (i) represents the $\mathrm{NAD}(\mathrm{P}) \mathrm{H}$ oscillations obtained by fluorimetry of the same cell suspension $\left(10^{7}\right.$ cells $\left.\mathrm{ml}^{-1}\right)$. That the values of fluorescence intensity (arbitrary units) become negative means that the field of cells is brighter than the internal standard (see Methods). 
(a)
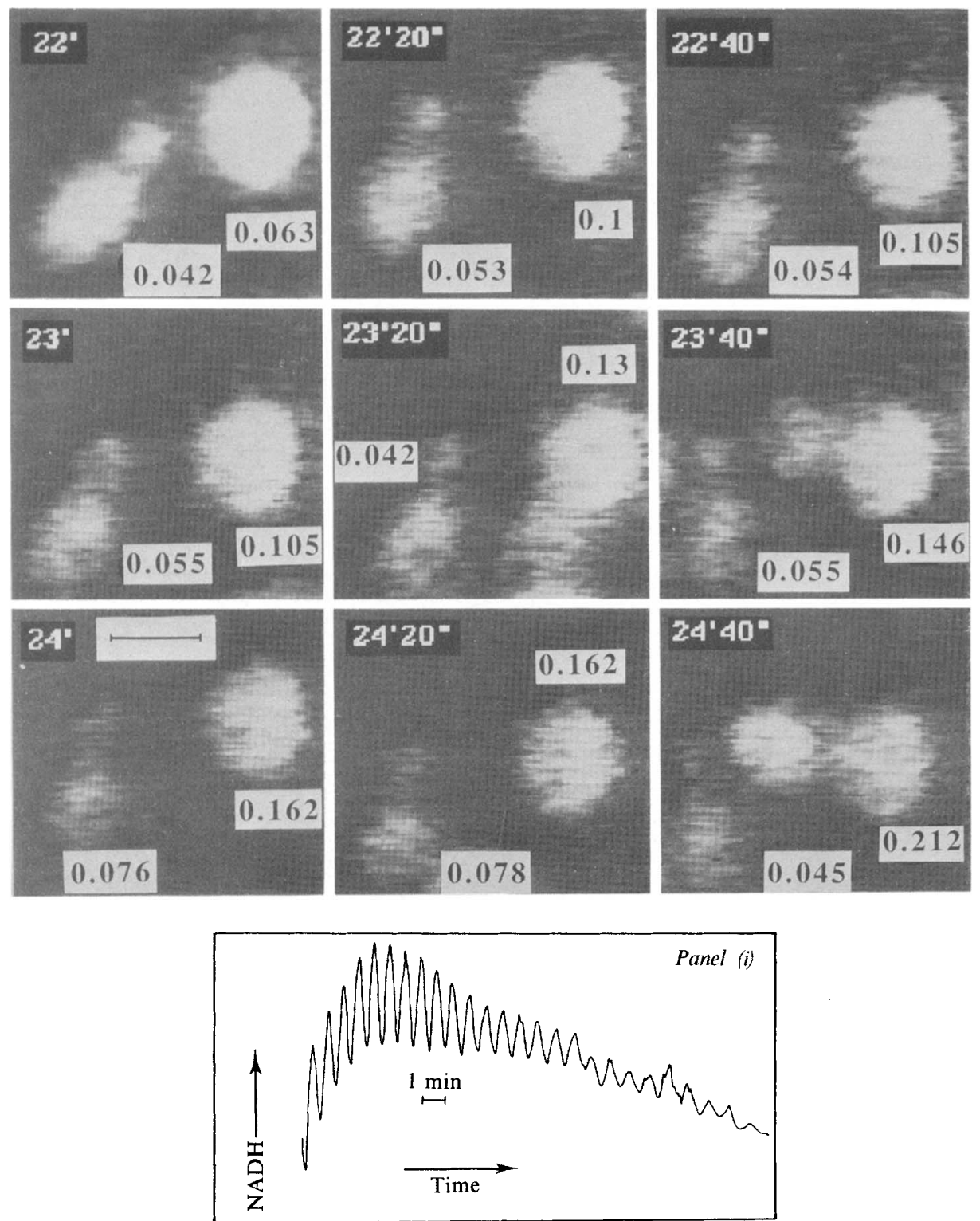

(b)
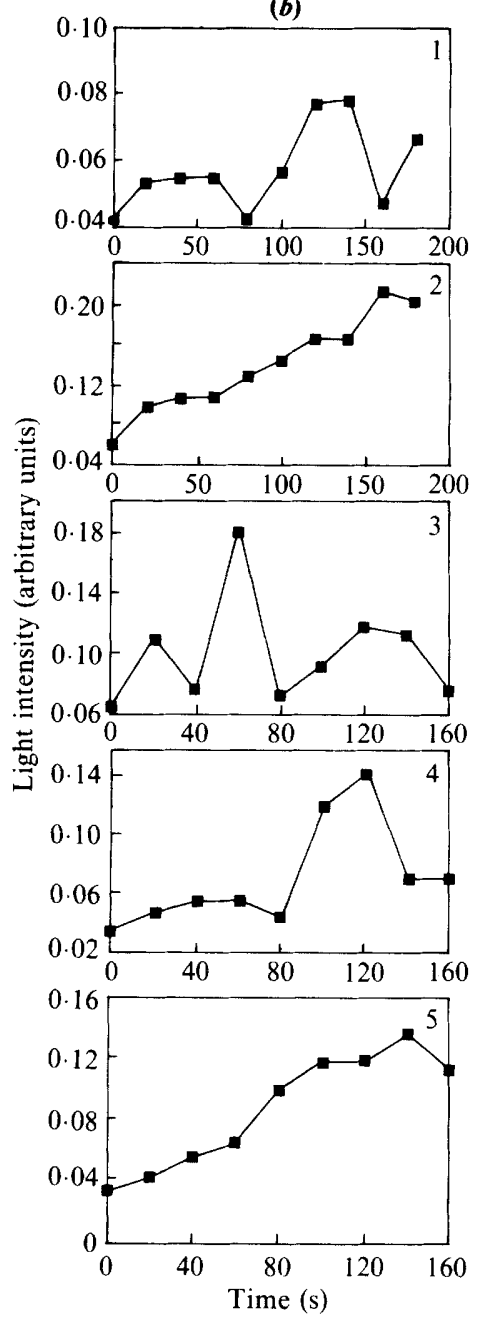

Fig. 3. Image analysis from video films of starved yeast under oscillatory conditions at the single and cell population levels. Glycolytic

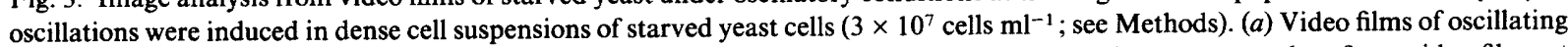
yeast cells (excitation at $340 \mathrm{~nm}$, emission at $450 \mathrm{~nm}$ ) were made as described in Methods. Pictures were taken from video films at regular intervals $(20 \mathrm{~s})$ and the images were analysed. Within $22 \mathrm{~min}$ of addition of KCN, the oscillations had already dampened macroscopically (see panel i) as indicated by a parallel fluorimetric test of the same cell batch. Numbers on the video film pictures indicate the fluorescence intensity values normalized per unit area. (b) The temporal changes in fluorescence were followed in ten cells. The fluorescence values are reported for five representative individual cells. Panels 1 and 2 represent the fluorescence kinetics of the two cells shown in $(a)$. The fluorescence intensity values indicated on the $y$-axis are normalized per unit area to allow comparison of different cells and time sequences of the same cell due to slow cell rotation, e.g. the budded cell at the right of the pictures sometimes appears as a single cell. Cells were not stuck to the glass surface because it is known that metabolic changes are introduced by cell immobilization (Galazzo \& Bailey, 1989).

macroscopic oscillation. The simulation results obtained support the notion that differences in oscillatory dynamics at the single cell level may well contribute to the macroscopic damping by loss of synchrony: individual oscillators go out of phase.

\section{Metabolic basis of cell interaction}

At concentrations of $3-5 \times 10^{7}$ cells $\mathrm{ml}^{-1}$, glucose addition alone caused oscillatory transients of NAD $(\mathrm{P}) \mathrm{H}$ fluorescence (Fig. 4a). Also, very dense cell suspensions $\left(5 \times 10^{8}\right.$ cells $\left.\mathrm{ml}^{-1}\right)$ stored for $1-4 \mathrm{~h}$ on ice and then 


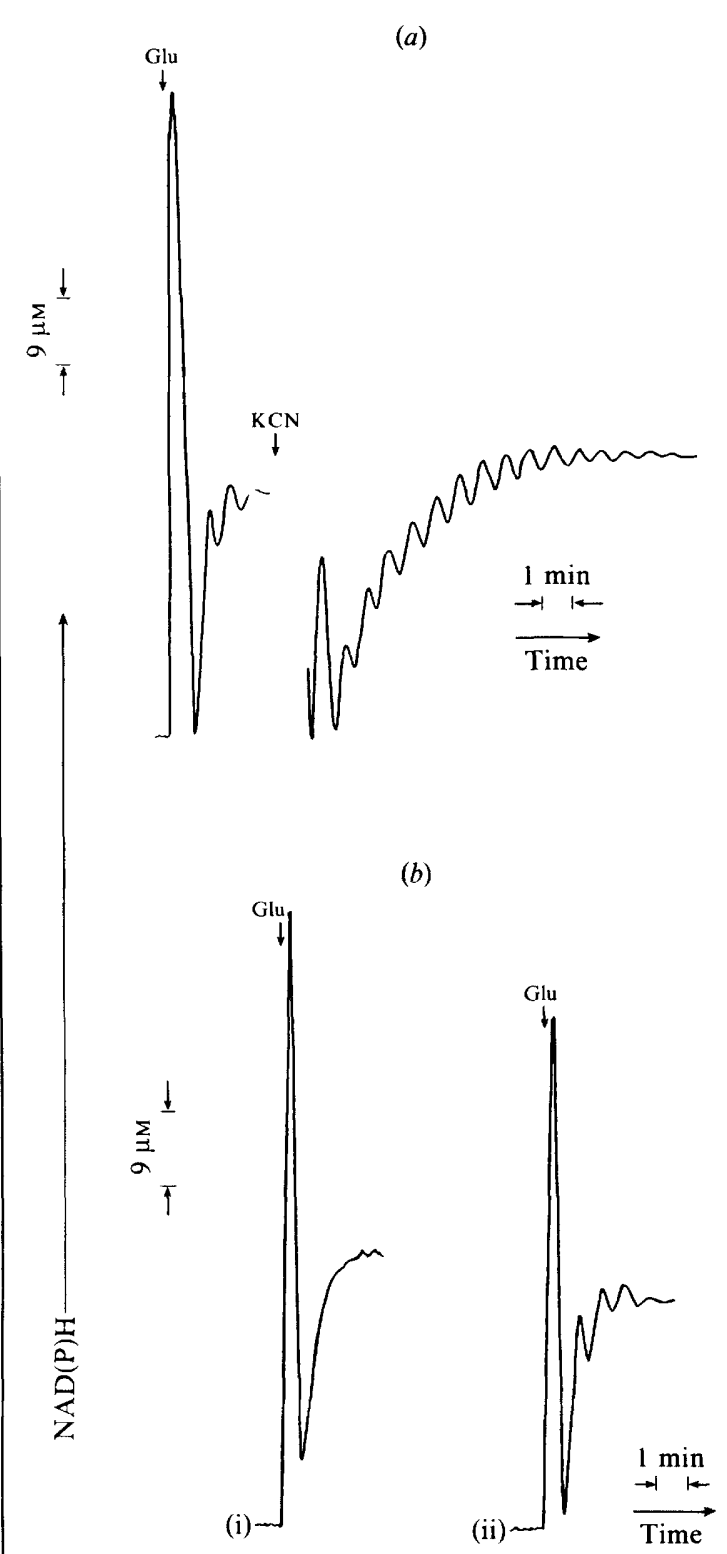

Fig. 4. Ethanol-induced oscillatory transients. Starved yeast cells were pre-incubated with stirring for $2 \mathrm{~min}$ at $25^{\circ} \mathrm{C}$ in the fluorimeter cuvette in the absence $(a)$ and presence $(b)$ of ethanol before addition of $20 \mathrm{~mm}-$ glucose or $15 \mathrm{mM}-\mathrm{KCN}$. (a) $3 \times 10^{7}$ cells ml $\mathrm{m}^{-1}$. (b) $10^{7}$ cells $\mathrm{ml}^{-1}$; trace (i) control without ethanol addition; trace (ii) $10 \mu \mathrm{M}$-ethanol. Arrows indicate glucose (Glu) and $\mathrm{KCN}$ additions.

diluted to $10^{7}$ cells $\mathrm{ml}^{-1}$ exhibited oscillatory transients upon addition of glucose. When the same dense cell suspension was diluted, centrifuged and resuspended in fresh buffer, oscillatory transients were not triggered by glucose addition (results not shown). This suggested that a compound excreted by the cells plays an essential role in the oscillations. Supernatants of dense cell suspensions
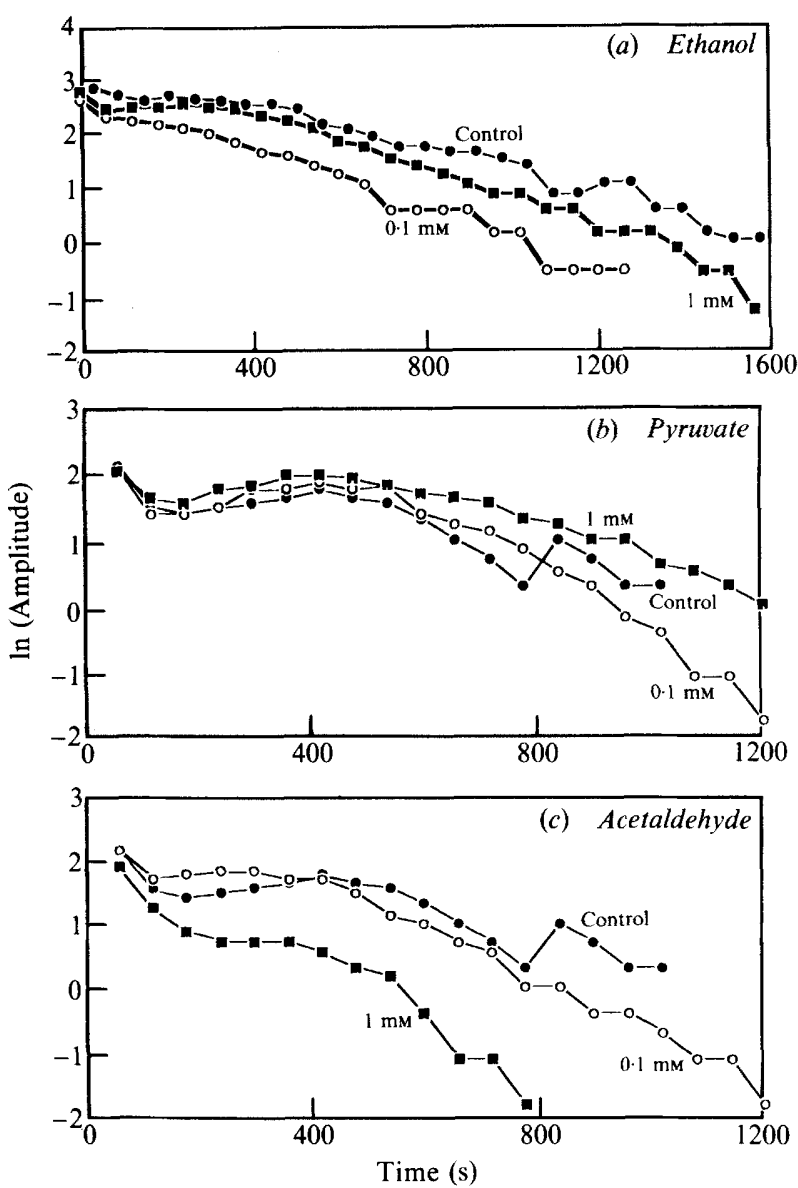

Fig. 5. Changes in the amplitude of oscillations with time at high cell densities in the presence of ethanol $(a)$, pyruvate $(b)$ and acetaldehyde (c). Starved yeast cells were pre-incubated with stirring for $2 \mathrm{~min}$ at $25^{\circ} \mathrm{C}$ in the fluorimeter cuvette in the absence ( ; control) or presence of two different concentrations $(O, 0.1 \mathrm{~mm} ; \mathbf{D}, 1 \mathrm{~mm})$ of ethanol, pyruvate and acetaldehyde before addition of $20 \mathrm{~mm}$-glucose and $15 \mathrm{mM}-\mathrm{KCN}$. The amplitude of oscillations was followed as described in Fig. 1.

(3-5 $\times 10^{7}$ cells $\left.\mathrm{ml}^{-1}\right)$ were assayed for presence of ethanol, pyruvate and acetaldehyde. Ethanol $(0 \cdot 1-$ $0.2 \mathrm{~mm}$ ) could be detected; pyruvate and acetaldehyde could not (lower detection limit: $1 \mu \mathrm{M}$ ). In order to analyse the conditions under which a glycolytic product such as ethanol or glycolytic intermediates such as pyruvate and acetaldehyde could participate in the cell interaction phenomenon observed (Fig. 1), experiments were performed to investigate whether these metabolites could effectively be metabolized in the presence of glucose and could thus affect glycolytic oscillations.

\section{Ethanol and glycolytic intermediates as putative intercellular messengers}

Starved yeast cell suspensions $\left(10^{7}\right.$ cells $\left.\mathrm{ml}^{-1}\right)$ actively respired in the presence of $0.1 \mathrm{mM}$-ethanol $(22 \mu \mathrm{M}$ - 


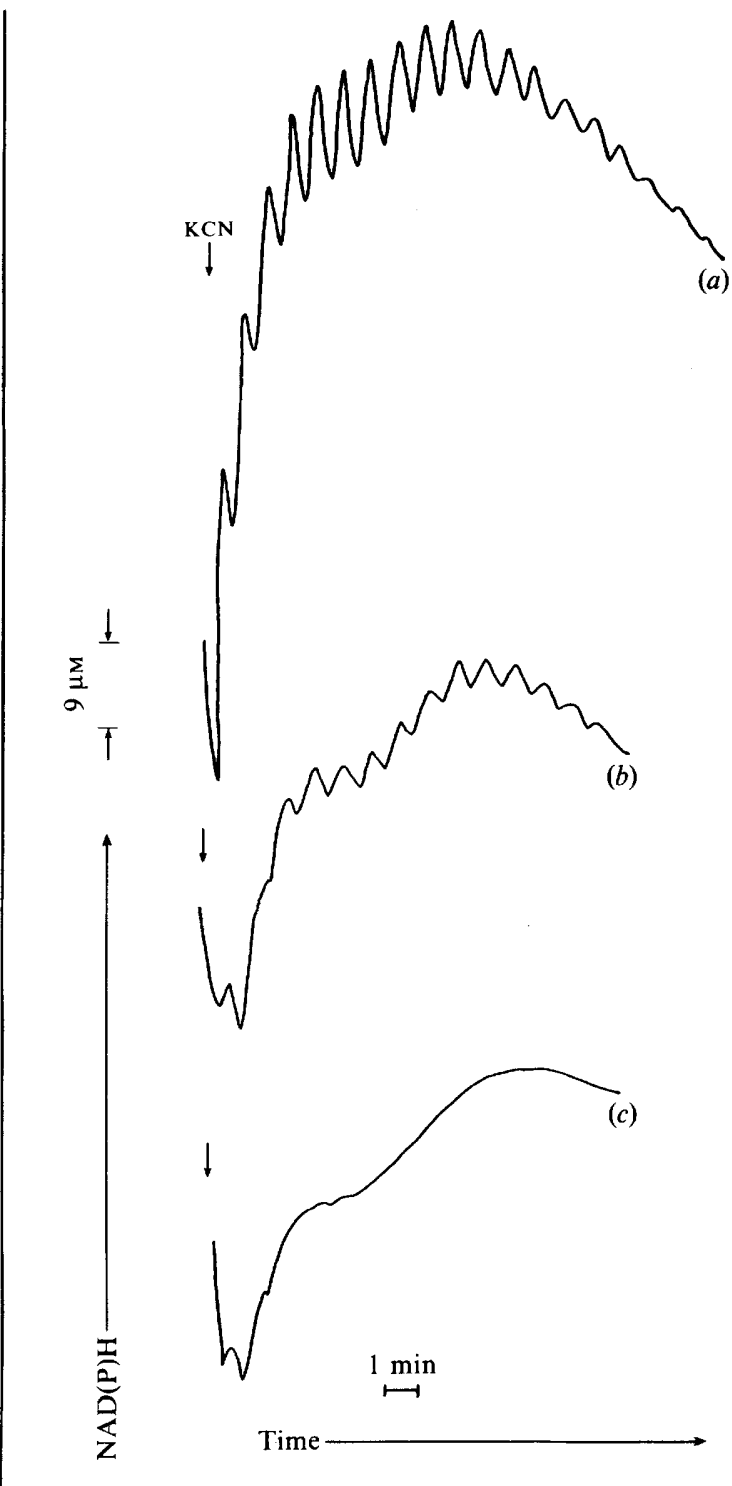

Fig. 6. Disappearance of oscillations at high cell concentrations after inhibition of the ethanol oxidative pathway with pyrazole. Starved yeast cells were pre-incubated with stirring for $2 \mathrm{~min}$ at $25^{\circ} \mathrm{C}$ in the fluorimeter cuvette in the absence (trace $a$ ) or presence of $0.6 \mathrm{mM}$ (trace $b$ ) and $1.2 \mathrm{~mm}$ - (trace $c$ ) pyrazole before addition of $20 \mathrm{~mm}$ glucose (trace not shown) and $15 \mathrm{~mm}-\mathrm{KCN}$ (arrows).

$\mathrm{O} \min ^{-1}$ ) and doubled their respiration rate when a similar amount of ethanol was added. Addition of $20 \mathrm{~mm}$-glucose provoked an increase of approximately $45 \%$ in the rate of respiration. Only a slight increase $(10 \%)$ in respiration rate was observed when ethanol $(0 \cdot 1$ or $1 \mathrm{mM}$ ) was added to cells already respiring in the presence of $20 \mathrm{mM}$-glucose. The cells reached similar rates of respiration under the two experimental conditions of cosubstrate utilization described above, perhaps due to limited respiratory capacity (Rieger et al., 1983).
Oscillatory transients triggered by glucose addition alone could be observed in washed resuspended yeast cells pre-incubated for $2 \mathrm{~min}$ in the presence of ethanol $(0.01-0 \cdot 1 \mathrm{mM})$ (Fig. $4 b)$. This experimental evidence, and the fact that starved yeast cells were able to metabolize glucose and ethanol simultaneously, agree with the possibility that extracellular ethanol affects the oscillations in individual cells.

After triggering oscillations by $\mathrm{KCN}$ addition at high cell densities $\left(3 \times 10^{7}\right.$ cells $\left.\mathrm{ml}^{-1}\right)$, the ethanol concentration rose almost exponentially after a lag of $3 \mathrm{~min}$. To ascertain whether ethanol may play a role in keeping cells synchronous, the kinetics of damping of KCNtriggered oscillations at high cell densities was studied in starved yeast cells pre-incubated with ethanol. At low cell densities $\left(10^{7}\right.$ cells $\left.\mathrm{ml}^{-1}\right)$ ethanol did not induce changes in damping (not shown). At high cell densities $\left(3 \times 10^{7}\right.$ cells $\left.\mathrm{ml}^{-1}\right)$, the lower ethanol concentration especially appeared to increase damping (Fig. $5 a$ ). The role of ethanol in promoting oscillations at high cell densities was further confirmed by treatment of yeast cell suspensions $\left(3 \times 10^{7}\right.$ cells $\left.\mathrm{ml}^{-1}\right)$ with pyrazole, an inhibitor of alcohol dehydrogenase II (Lieber et al., 1978). Increasing concentrations of pyrazole (from 0.6-1.2 mM) first augmented the damping and the amplitude of the oscillations (Fig. 6), then quenched the oscillations (Fig. 6).

The effect of pyruvate and acetaldehyde was also investigated. Both at low (not shown) and at high (Fig. 5c) cell concentrations, acetaldehyde increased the damping factor while pyruvate showed a behaviour similar to ethanol either at low or high cell densities (Fig. 5b).

\section{Discussion}

Glycolytic dynamics of individual cells, and their tendency to oscillate and the frequency of oscillation, are likely to be affected by the flux balance of $\mathrm{NAD}^{+}$ reduction and NADH oxidation. The flux redox balance is accomplished, on the one hand, through pathways reducing $\mathrm{NAD}(\mathrm{P})^{+}$, such as ethanol catabolism, and on the other hand the pathways oxidizing $\mathrm{NAD}(\mathrm{P}) \mathrm{H}$, such as dihydroxyacetone phosphate reduction. The net effect of these two types of pathway functions against the background of glycolysis, which, in principle operates at a much higher throughput (in the presence of cyanide). Because glycolysis is redox neutral in terms of causing no net NAD $(\mathrm{P})^{+}$reduction, yet depends dynamically on the redox state of $\mathrm{NAD}^{+}$, the dynamic redox balance is likely to be an important determinant of glycolytic oscillations. The present work shows that in oscillating populations of yeast, individual cells influence the glycolytic dynamics of other cells. Yet, primarily, the oscillations are 
oscillations of individual cells. Because of slight kinetic heterogeneity, the oscillation of the population damps more quickly than that in individual cells. We propose that the cells affect each others' dynamic redox balance through an increasing concentration of extracellular ethanol arising from ethanol produced intracellularly. This concentration increases with both time and cell density.

The 'cosubstrate model' leading to the explanation described above is an extension of a previous model (Cortassa et al., 1990; Aon et al., 1991; Aon \& Cortassa, 1991), with the following features: (i) ethanol is utilized in an oxidative pathway; (ii) the flux balance between $\mathrm{NAD}^{+}$reduction and NADH oxidation at the single cell level is the biochemical determinant of autonomous cellular glycolytic oscillations; (iii) ethanol produced by glycolysis and equilibrating with the medium subsequently affects the oscillatory dynamics of the cells by affecting the redox balance; (iv) additional reactions oxidize $\mathrm{NAD}(\mathrm{P}) \mathrm{H}$; one of these could reflect leakage through the cyanide block and the other reduction of dihydroxyacetone phosphate. This model, simulated without cell-to-cell interaction, assumes that the population is dynamically homogeneous. Before macroscopic damping, the assumption of homogeneity appears reasonable in the light of the results shown in Fig. 2.

Several experimental observations were simulated, and explained, by the model. (1) Oscillatory transients triggered by glucose when ethanol was present (cyanide being absent) (Fig. 4) may be due to high ethanol inputs (results not shown). It has indeed been shown that ethanol is consumed under those conditions. The respiration measurements are in agreement with high rates of ethanol utilization (see text).

(2) Low ethanol concentrations enhanced the oscillations, whereas higher ethanol concentrations lead to continued reduction of $\mathrm{NAD}(\mathrm{P})^{+}$and damping of the oscillations. In the absence of such added ethanol, one expects the ethanol concentration in the suspension to increase both with time and with cell density. This might then cause individual cells to sense the cell density, resulting in the apparent interaction between cells.

(3) At low cell densities, calculations based on the model led to damped oscillations, while at higher cell densities an initial phase of oscillations slightly decreasing in amplitude was calculated to be followed by a subsequent phase where the oscillations remained almost constant in amplitude. At still higher cell densities, the amplitude of the oscillations again decreased more quickly. According to these calculations, our experimental observations that with increasing cell density the oscillations damp less quickly can be explained. Essentially, the reason is that within a certain concentration range ethanol enhances the oscillations because it brings the redox level of $\mathrm{NAD}(\mathrm{H})$ to an optimum. At high cell densities, the ethanol produced by the cells is sufficient to bring the extracellular ethanol concentrations to this level. Upon continued incubation, the ethanol concentration may increase further, bringing it into the region where it negatively affects the oscillations, because the redox level of $\mathrm{NAD}(\mathrm{H})$ becomes too reduced. The model allows two further experimental observations to be understood. A strong decrease in the amplitude of oscillations was noticed when $1 \mathrm{mM}$-acetaldehyde was added (Fig. 5c). As with added ethanol, acetaldehyde may disturb the redox balance and hence the glycolytic oscillations (Gancedo \& Serrano, 1989; Van Urk et al., 1989).

(4) If the oxidation of ethanol in the catabolic pathway promotes oscillations at high cell densities, then inhibition of the former should quench the oscillations. Pyrazole, a potent inhibitor of alcohol dehydrogenase II (which catalyses the first step of the ethanol oxidative pathway), was used in order to test this hypothesis (Lieber et al., 1978). Pyrazole (1.2 mM), at high cell densities $\left(3 \times 10^{7}\right.$ cells $\left.\mathrm{ml}^{-1}\right)$, inhibited the oscillations (Fig. $6 c$ ). Low pyrazole concentrations $(0.6 \mathrm{mM})$ drastically decreased the amplitude of the oscillations and increased the damping (Fig. $6 b$, and results not shown).

Pye (1973) observed that a metabolic switch occurred when oscillations damp out concomitantly with a sharp drop in the rate of ethanol production. With the cosubstrate model, this observation may be attributed to a redox imbalance in the cells triggered by hypoxia. Indeed, in our simulations for the presence of high ethanol concentrations, it was observed that glycolysis tended to be inhibited. When acetic acid is produced by the ethanol oxidative pathway, an excess of NADH is expected. This cannot be compensated by redox-neutral glycolytic ethanol production, so a kind of 'Custer's effect' then arises (i.e. inhibition of alcoholic fermentation in the absence of oxygen) (Van Dijken \& Scheffers, 1986).

We thank L. J. W. M. Oehlen for help in the centrifugal elutriation experiments, N. J. H. Raat and E. van Spronsen for advice in image analysis, R. Belleman for help in software installation and the National Biomedical Simulation Resource (Duke University, Durham, USA) for assistance in the use of SCoP, 1987. Discussions with D. Kahn and $\mathbf{R}$. van Driel are also acknowledged. We are indebted to the Department of Molecular Cell Biology, University of Amsterdam for video and image analysis facilities. S.C., M.A.A. and H.V.W. thank the Commission of European Communities and The Netherlands Organization for the Scientific Research (NWO) for financial support.

\section{References}

Aldridge, J. \& Pye, E. K. (1976). Cell density dependence of oscillatory metabolism. Nature, London 259, 670-671.

Aon, M. A., Cortassa, S., Westerhoff, H. V., Berden, J. A., van SPRonsen, E. \& VAN DAM, K. (1991). Dynamic regulation of yeast 
glycolytic oscillations by mitochondrial functions. Journal of Cell Science 99, 2325-2334.

AON, M. A. \& CoRTASSA, S. (1991). Thermodynamic evaluation of energy metabolism in mixed substrate catabolism. Modelling studies of stationary and oscillatory states. Biotechnology and Bioengineering 137, 197-204.

Chance, B., Williamson, G., Lee, I. Y., Mela, L., DeVault, D., Ghosh, A. \& PYE, E. K. (1973). Synchronization phenomena in oscillations of yeast cells and isolated mitochondria. In Biological and Biochemical Oscillators, pp. 285-300. Edited by B. Chance, K. Pye, A. K. Ghosh \& B. Hess. New York: Academic Press.

Cortassa, S., AON, M.A . \& Thomas, D. (1990). Thermodynamic and kinetic studies of a stoichiometric model of energetic metabolism under starvation conditions. FEMS Microbiology Letters 66 , 249-256.

Galazzo, J. L. \& Bailey, J. E. (1989). In vivo nuclear magnetic resonance analysis of immobilization effects on glucose metabolism of yeast Saccharomyces cerevisiae. Biotechnology and Bioengineering 33, 1283-1289.

GaNCEDo, C. \& SERRANo, R. (1989). Energy-yielding metabolism. In The Yeasts, vol. 3, pp. 205-259. Edited by A. H. Rose \& J. S. Harrison. London: Academic Press.

Ghosh, A. K., Chance, B. \& Pye, E. K. (1971). Metabolic coupling and synchronization of NADH oscillations in yeast cell populations. Archives of Biochemistry and Biophysics 145, 319-331.

Hess, B. \& Borteux, A. (1971). Oscillatory phenomena in biochemistry. Annual Review of Biochemistry 40, 237-258.

Lieber, C. S., DeCarli, L. M., Matsuzaki, S., Ohnishi, K. \& TESCHKE, R. (1978). The microsomal ethanol oxidizing system (MEOS). Methods in Enzymology 52, 355-367.
Lloyd, D., Poole, R. K. \& Edwards, S. W. (1982). The Cell Division Cycle. Temporal Organization and Control of Cellular Growth and Reproduction. London: Academic Press.

Nicolis, G. \& PRIGOGINE, I. (1977). Self-organization in Nonequilibrium Systems. New York: John Wiley.

Oehlen, L. J. W. M., van Doorn, J., Scholte, M. E., Postma, P. W. \& VAN DAM, K. (1990). Changes in the incorporation of carbon derived from glucose into cellular pools during the cell cycle of Saccharomyces cerevisiae. Journal of General Microbiology 136 , 413-418.

PYE, K. E. (1973). Glycolytic oscillations in cells and extracts of yeast. Some unsolved problems. In Biological and Biochemical Oscillators, pp. 269-284. Edited by B. Chance, K. Pye, A. K. Ghosh \& B. Hess. New York: Academic Press.

Rieger, M., KaPelli, O. \& Fiechter, A. (1983). The role of limited respiration in the incomplete oxidation of glucose by Saccharomyces cerevisiae. Journal of General Microbiology 129, 653-661.

VAN DiJken, J. P. \& Scheffers, W. A. (1986). Redox balances in the metabolism of sugars by yeasts. FEMS Microbiology Reviews 32, 199-224.

Van Urk, H., Schipper, D., Breedveld, G. J., Max, P. R., SCheffers, W. H. \& Van Dijken, J. P. (1989). Localization and kinetics of pyruvate-metabolizing enzymes in relation to aerobic alcoholic fermentation in Saccharomyces cerevisiae CBS 8066 and Candida utilis CBS 621. Biochimica et Biophysica Acta 992, 78-86.

WINFrEE, A. T. (1980). The Geometry of Biological Time, pp. 285-299. New York: Springer Verlag. 